\title{
Mathematical Argumentation of Students Participating in a Mathematics - Information Technology Project
}

\author{
Nikolaos Metaxas (Corresponding author) \\ Evangeliki School of Smyrna, Athens \\ Lesvou 4, Athens 17123, Greece \\ E-mail:nkm1012gr@yahoo.com
}

Received: December 11, 2014 Accepted: January 14, 2015 Published: January 20, 2015

doi:10.5296/ire.v3i1.6767ＵRL: http://dx.doi.org/10.5296/ire.v3i1.6767

\begin{abstract}
The paper focuses on the analysis of mathematical argumentation of grade 7 students that participated in a joint mathematics-information technology project that had the form of an open problem. We combined the tools of Toulmin's model -by measuring the density of the arguments in the basic argument elements- and that of argumentation schemes in order to trace any change across the course in these two parameters. As the results showed, the inquiry based approach of the project in conjunction with the open discourse environment of the course, resulted in a significant change in students' argumentation. Their arguments became denser and more abstract in the sense of the schemes employed.
\end{abstract}

Keywords: Open problem; Mathematics and Computer Science; Argumentation Analysis, Toulmin, Argumentation Scheme

\section{Introduction}

Argumentation in a learning context, as a special form of social interchange, is considered to be essential in the construction of knowledge (Schwarz, Neumann, Gil, \& Ilya; 2003). According to Krummheuer and Brandt (2001), students can learn mathematics by participating in argumentation within social interaction as a collective activity. Nevertheless, there are not many research studies covering the critical space of identification of the changes that occur to students involved in argumentative tasks.

In this paper we attempt to contribute to the discussion regarding the employment of methodological tools for studying construction of knowledge in argumentative tasks. We analyse the argumentative speech of a group of 7th graders in the context of an open problem 
project using the methodologies we developed. We use the Toulmin (1958) analysis of argument structure and the relatively new concept of argumentation schemes mainly developed by Walton (2006). The context we use is that of an open-problem project where technology (in the form of information science) and mathematics are blended in order to achieve a solution. In this discourse-oriented environment, students split in groups, are encouraged to conjecture, explain, question, debate and cooperate with their peers until they reach a final result in their quest.

\section{Open Problems}

As a part of the attempts to find a new teaching method that could be more effective and promote creativity, open-problem approach was developed in the 1970's in Japan (e.g. Nohda, 2000). It is considered that open learning environments constitute a powerful method in mathematics teaching, since it supports conceptual understanding and development of resourcefulness (Stacey, 1995). Within such environment, students can deal with real problems, be active and develop creative imagination. Active learning, as it happens in open problem situations, embeds students into a realistic and contextual problem solving environment melding real life and the classroom (Blumenfeld et al., 1991).With the term open problem (or open task) we describe a task that its starting or goal situation is not exactly given (Pehkonen, 1995). In open tasks, students are given freedom, sometimes even in the formulation of the questions, and in the solving method of the problem. They may add different conditions and restrictions, thus ending up with different, but equally correct solutions. In this way students act as creative mathematicians and mathematical notions obtain personal meaning for them. When students are involved in solving an open task, are not always able to identify the most prominent ideas that are necessary to their problem. A suitable response for a teacher would be to refocus their attention and scaffold their learning by giving them the opportunity to develop their own understanding rather than relying on teacher's explanation (Anghileri, 2008). These are the general principles that the (computer science and mathematics) teachers of the project agreed to adhere to.

\section{Argumentation Analysis}

It is generally true that construction of knowledge can be obtained through the application of general skills to access knowledge and to construct and evaluate arguments (Means \& Voss, 1996). The construction of knowledge emerges from reasoning or the evaluation of the soundness of a claim. Research has indicated that argumentation as part of informal syllogism, is positively correlated to knowledge construction (Schwarz et al., 2003).

The two frameworks we employed in order to analyze students' arguments were Toulmin's model and the argumentation scheme approach. When students explore a mathematical task, express their ideas, or evaluate their peers' claim, they have to construct arguments in the public discourse space. Public conversation constitutes a rich window into analysing how students in a group are coordinating and making use of mathematical knowledge bases.

The classical approach to reconstruction of the structure of an argument is Toulmin's model. Toulmin (1958) has claimed that the traditional formal logical analysis of arguments is not 
rich enough to include parts of common arguments such as qualified conclusions, attack against other arguments and inference licenses. He proposed a model for the layout of arguments that consists of six basic parts, each of which plays a different role in an argument. The claim (C) is the position or claim being argued for. The data (D) are the foundation or supporting evidence on which the argument is based. The warrant (W) is a general rule of inference that authorises the step from the data to the claim. Warrants operate at a higher level of generality than a claim or reason, and they are not normally explicit. The Backing (B) supports the legitimacy of the warrant. Since Krummheuer (1995), a significant corpus of research has been taken place using Toulmin's scheme in mathematics education. Some researchers have focused on analysis of (mainly classroom-based) mathematical arguments of students, including usage of proof in general (Yackel, 2001), number skills (Evens \& Houssart, 2004), geometry (Pedemonte, 2007) and algebra (Pedemonte, 2008).

In order to gain a complementary and qualitative view on the arguments used, which could enable us to understand better the subject's content knowledge, we employed the theory of argumentation schemes. Toulmin's model describes the structure of an argument giving its components, but it does not reveal anything about the quality of this argument. The content of the Warrant and the Banking in an argument is crucial for the evaluation of this argument. For this reason, we complement Toulmin's model with a useful tool in argumentation theory: the theory of argumentation schemes. The argumentation schemes are stereotypical patterns of defeasible reasoning that represent different types of plausible argument used in everyday discourse, as well as in special contexts like those of scientific and legal argumentation. Standard accounts of argumentation schemes describe them as representing different types of plausible argument which, when successfully deployed, create presumptions in favour of their conclusions (Godden \& Walton, 2007). The basic argumentation schemes that we use in our research: abductive from sign, from classification, from illustration, from example and from consequences (Walton, Reed, \& Macagno, 2007). Schemes, in the way we employ them, do not get integrated in Toulmin's structure but act complimentarily in a qualitative way. For example, looking at an argument as a D, C, W, B simplex is not informative about the semantic content it carries. On the other hand, being able to characterize the inference as a scheme from -let's say- classification, is indicative of the reflective thought underlying the argument. Using the classification scheme, the subject focus on some abstract characteristics of the object under consideration, thus enabling him to make some inferences.

The classification of an argument according to argumentation scheme theory adds a qualitative perspective to our Toulmin analysis. An argumentation scheme is the expression of a warrant or a banking as a form of an argument rather than a statement. The kind of scheme in use could reveal more about the rationale (and hence the knowledge) that underlies it. Identifying the argumentation scheme of an argument involves a finer-grained analysis, compatible with a Tulmanian conception of the components of the argument. Both perspectives are necessary, complementary and indispensable with Toulmin's model revealing the structure and "static" form of an argument. On the other hand the scheme approach captures the dynamic form and subtleties hidden behind it. Associated with each argumentation scheme is a set of critical questions to be used in the evaluation of arguments 
of the corresponding type. The posing of a critical question has the effect of defeating the initial presumption and shifting the burden of proof back on to the initial proponent. Thus, critical questions are a kind of evaluative 'topoi' (as in Aristotele), providing a list of individually necessary conditions for the success of particular schematic arguments (Godden \& Walton, 2007). A similar approach, combining the two approaches we will follow concerning argumentation analysis, namely Toulmin's model and schemes, has also been reported (though in a different setting) in (Metaxas, Potari, \& Zachariades, 2009).

\section{The Project: Mathematical Constructions with the Aid of Information Technology}

The construction of knowledge during argumentation is sensitive to context (materials and artefacts, social interactions and goals of the participants) so it is important to take into account the specifics of the context that the study is taking place. The project took place in a grade 7 class of an exemplary urban middle school and was developed in cooperation with the mathematics and computer science teachers of these classes. In total 72 students participated that were divided into 3 classes of 24 each (since the laborattory of information class contains 12 computers, the usual arrangement is that each computer is shared by two students). The project was consistent with the computer science curriculum of this class which allows for the development and the employment of projects that incorporate methods of inquiry based learning in conjunction with other science disciplines. The overall goal of the project was to engage students in the discovery and construction of mathematical knowledge as they try to solve a problem involving elements of mathematics and computer programming. The students, after a visit to an exhibition with works by Escher, Vasarelly and Mondrian were allowed to choose (working in teams of four) a work of any of these that would use as an inspiration in order to create a work on their own using some basic programing tools and applications (as Turtle Art ${ }^{\circledR}$, Geogebra ${ }^{\circledR}$ etc). The students had not only to master really well the app that they chose to use, but in order to employ effectively the programming tools they had to solve (depending on their particular choice) a series of problems of pure mathematical nature: the kind of geometrical transformations needed and basic properties of these, the minimal section of a figure needed to serve as a basic element, calculating ratio, angles, arc lengths and segments, and in a couple of cases Pythagorean theorem. The mathematical concepts required were in some cases unknown to them, so they had to investigate and discover them -with limited assistance from their teacher- in order to investigate and solve the problem they dealt with. The students had no prior experience with the use of the computer programs and certain mathematical concepts they encountered were completely new knowledge to them. So from the very beginning their challenge was twofold: to analyze the problem posing the right questions and planning the solution and to comprehend the (mathematical and computer) tools needed to implement their path of action. The groups of students had only the absolutely necessary instructions when stuck, either in information science or in mathematics. The group of 4 students we will focus on chose to construct a synthesis of repeated lizards as in the homonymous drawing by Escher. 


\section{Research Questions}

The researchers' observation of the interactions between the students during the class hours and their attitudes as recorded in interviews with them, informed the following two research questions:

- What is the change (if any) in mathematical argumentation of students?

- What does the argumentation analysis of the students' dialogues reveals about their learning and their construction of mathematical knowledge?

\section{Methodology}

The population consisted of 72 grade 7 students. The project sessions were held during the first two trimesters of the school year (September to March). The first two and the last two (11th and 12th) of the project sessions were audio recorded. After an initial interpretation based on the recorded samples a detailed analysis were carried, with the aid of the chosen argumentation models. An overall interpretation of the recorded material led to preliminary interpretations. Then some of the data that were considered not relative to the mathematical content were eliminated. Finally the situations were analysed using argumentation analysis techniques. In order to eliminate any discrepancy among our argument evaluations, we included a comparison of the characterizations that each member of the research team made. Whenever there was a difference, a deeper analysis was conducted until a consensus was reached. We used triangulation of the initial results obtained, by means of a second shorter interview with each student, where he/she commented on our own interpretations. It resulted in new and deeper perspectives of what took place in the classroom sessions. In this paper certain indicative passages will be cited and discussed in order to better clarify our results.

\section{Results and Analysis}

We present three different episodes and analyze the arguments that the students use. The first episode consists.

\subsection{Episode 1: Studying the Problem of the Construction of the Drawing}

The four students of this group picked up a drawing by Escher (namely: The Lizard, 1942) and tried to create a similar computer-based drawing on their own. After drawing by hand several sketches they choose one and they used it as a prototype of the drawing they would create with the aid of software Turtle Art ${ }^{\circledR}$. During the first three sessions they attempted to analyze the mathematical and symmetrical aspects of their sketch in order to be able to transfer its properties into programming commands. The excerpt is from the fourth session in class where they debate on the way to produce a rotation of their basic unit. The students are denoted by the initials $\mathrm{S}, \mathrm{T}, \mathrm{U}$ and $\mathrm{V}$.

01: S: Well, if you rotate this lizard like this you end up with the next lizard.

02: T: No, if you do it like you said, you get one lizard above the other.

03: U: Guys we should move it first and then rotate. 
Student U shows what she means with some hand waving and then they write down their moves. After a while, as they try to figure out what kind of commands they will use to describe what they found, they realize that they need an invariant point (center) of rotation at each stage.

04: T: Now, to rotate, we need something around which to rotate the lizard.

05: V: If we take the center of the lizard.

(Points towards a common point of the first and the second lizard)

06: U: Why take this point? Why is this the center?

07: V: It's the centre because it is equidistanced from all points.

08: T: It doesn’t seem it is equidistanced from all the points [of lizard].

09: V: It's what the textbook says, the definition of circle...

At this point student $\mathrm{V}$ shows a practical manner to make the rotation needed to get another lizard. His argument could be analyzed, using Toulmin's model as follows:"

D: rotating the first lizard around a specific point one gets the second lizard.

$\mathrm{C}$ : the center of (rotation of) the lizard is that particular common point of the first and the second lizard.

$\mathrm{W}$ : because it is equidistanced from all points.

B: It's what the textbook says, the definition of circle.

Student $\mathrm{U}$ in order to support his claim (and rebut the question by his peer) uses an argument that contains a warrant and a backing, making it structurally quite dense. On the other hand, his argumentation scheme is a combination of scheme from analogy and scheme from expert opinion, since his backing is based on a (supposed) similarity to the (authoritative) definition of center contained in mathematics textbook. Obviously the scheme from analogy is weak (the mathematical concept of a circle's center doesn't coincident with the center of rotation or center of symmetry) and so the scheme from expert opinion is not applicable. So even though U's assertion is almost full in the sense of the argumentative units he employs (data, claim, warrant and backing), the argument fitting the schemes he used are weak. This can be shown by considering the critical questions of scheme from analogy and from expert opinion. In the first case the critical question: are there differences between the two analogues that tend to undermine the force of the similarity, has an obvious affirmative answer. In the expert opinion scheme, paraphrasing critical question 2 from Walton, Reed and Macagno (2008), is the authority relevant to the case examined? has an obvious negative answer. This passage shows that even in cases where there were a dense argumentation speech from a student, their schemes were not always valid.

\subsection{What Was the Changes in the Argumentation of the Students?}

We examined the changes in the argumentation of the students, both in terms of the density of 


\section{Macrothink}

International Research in Education

ISSN 2327-5499

2015, Vol. 3, No. 1

Toulmin's elements and in the type of schemes employed. More specifically, we studied:

- the change of the ratio of argument elements, warrants and backings to the total number of arguments

- the change of the percentage of each scheme employed

Concerning the change of the ratio of argument elements, there is a significance increase in the number of argument elements between the first two and the last two sessions (Table 1). That is, more arguments had warrants and backings (since data and claims had almost all of them) in the last two sessions than in the first two. It is clear from Table 2 that while in the first sessions around 17\% of all the arguments, contained all four basic elements ( D,C,W \& B), in the last two sessions it was more than half of them (57.9\%). There was also an increase in the D-C-W complexes from $30.5 \%$ to $34.2 \%$.

Table 1. Average number of argument elements

\begin{tabular}{lllll}
\hline & $\bar{x}$ & $\mathrm{SD}$ & $\mathrm{t}$ & $\mathrm{p}$ \\
\hline 1st \& 2nd session * $^{*}$ & 2.64 & 1.02 & -3.61 & .001 \\
11th \& 12th session** & 3.50 & 0.90 & -3.70 & \\
\hline
\end{tabular}

$* \mathrm{~N}_{1}=36, * * \mathrm{~N}_{2}=38$ arguments.

Table 2. Percentage of arguments according to the elements that contain

\begin{tabular}{ccc}
\hline argument elements & 1st \& 2nd session & 11th \& 12 th session \\
\hline D,C & $52.7 \%$ & $7.9 \%$ \\
D,C,W & $30.5 \%$ & $34.2 \%$ \\
D,C,W,B & $16.8 \%$ & $57.9 \%$ \\
\hline
\end{tabular}

Regarding the schemes the students used, there is also a change in the types employed.

Table 3. Ratio of schemes to the total number of schemes

\begin{tabular}{ccc}
\hline Ratio of schemes to the total number of schemes & 1st and 2nd sessions & 11th and 12th sessions \\
\hline schemes from consequences & 0.3 & 0.2 \\
schemes from expert opinion & 0.3 & 0.1 \\
schemes from classification & 0.1 & 0.3 \\
schemes from example & 0.1 & 0.2 \\
scheme from sign (abductive scheme) & 0.2 & 0.2 \\
\hline
\end{tabular}

As seen from Table 3, there is a decrease in the schemes that belong to the 'practical reasoning' and 'source based' types [20] that is from consequences and from expert opinion. 
On the other hand we have an increase in schemes from example and from classification.

We give an example of each of the above mentioned schemes (except the scheme from expert opinion which already has been given above) that they were embedded in students' arguments (lines 10 and 12 are from the first two sessions):

10: T: I don't think we should start measuring angles in this way because we wouldn't end up with anything that could be parametrized (scheme from consequences).

11: U: Changing the scale we get bigger lizards but they are still lizards ... and the overall drawing is similar to the initial, so the he angle of rotation must be the same (scheme from classification).

12: T: These two lizards are symmetric about their common line which is an axis of symmetry ... so for every lizard in our sketch the common line with its adjacent lizard is the axis of symmetry (scheme from example).

13: S: It's clear that if the angle [of rotation of an equilateral triangle] takes the values $60^{\circ}$ or 1200 [multiples of $60^{\circ}$ ] we always get a tessellation ... we don't get a tessellation if the angle [of rotation] equals $90^{\circ}$ so the angle must be one of the multiples of $60^{\circ}$ [that is] $60^{\circ}$ or $120^{\circ}$ or $180^{\circ}$ (abductive scheme).

\section{Conclusion}

Students construct knowledge as they marshal evidence to argue that their chosen belief is supported by the given evidence and more warranted than other plausible beliefs (Schwarz et al., 2003). So in the process of exploring an open problem, they acquired general skills such as justifying, challenging, counterchallenging, or the acquisition of conceding. As an implicit goal they understood and constructed specific knowledge related to mathematics and programming. By analyzing the density of argument elements (using Toulmin's model) and the quality of inferences (using argumentation schemes) we could trace some significant trends in the development of their argumentation skills.

There is a significant 'densification' of the argumentation speech in the sense of using more supportive elements (warrants and backings). Their speech became better grounded, more supported and deeper due to the more backings that augmented the credibility of their claims, as we easily infer from Tables I and II. The increase in the quality of their reasoning is perhaps due to the fact that there was significant emphasis in the course on the need of explaining clearly and establishing as firmly as possible one's claim on solid support. Furthermore, by looking at Table III, we could notice a certain shift to more 'abstract' types of schemes (schemes from example and from classification) and a decrease in the practical schemes from consequences and in the authority oriented schemes (from expert opinion). This characterizes an improvement in the quality of their argumentation speech, since not only they use more support (warrants and backings) but also their schemes are more abstract and logical in structure (although schemes from consequences or from expert opinion can be also abstract, in the case of our 7th graders, they only used them in a practical or authoritative resp. way). Regarding the (abductive) schemes from sign that appear at a constant value in 
Table 3, it is not easy to draw a clear cut conclusion. The schemes from sign are easily defeasible since they are more empirical in nature. Nevertheless, they include the construction of conjectures, which was one of the goals of the course. So, although the before mentioned results indicate a more structured and robust argumentation speech, the steady ratio of schemes from sign may reveal the aspect of discovery and exploration that is inhered in problem solving.

The synthesis of the Toulmin's model and the argumentation schemes turned out to be a fitting tool to describe the development of students' argumentation. As students worked with their peers on an open problem, their need to understand each other and communicate their views and conjectures in order to reach a solution led to the need to better clarify and articulate their thoughts. It is an indication that in an open discourse environment, schemes of inference, like the ones used in everyday speech, can be transformed to strategies that assist the creation of ideas and the building of justification needed to support them. To inquire more into the structures of argumentation of the students and the knowledge that is reflected through these, a deeper analysis of the changes that occur has to be made. As has been shown elsewhere (e.g Cramer, 2011) a denser argumentation prevail in the development of epistemic processes, which corresponds to the gathering - combining and structure-seeing phases of the epistemic action model of Bikner-Ahsbahs (2005). Student interactions as they participate in small group discourse reveal emergence of new knowledge as they negotiate their meanings and explanations. In this case our findings comply with other empirical studies on the construction of new knowledge of students through a process of convergence/co-construction (Scardamalia \& Bereiter, 1994) and a process of dissemination/diffusion through the need to persuade and explain.

In sum, the technology project analysed reaffirms the position (e.g. Bungum, Manshadi, \& Atle Lysne, 2014) that an open discourse learning environment has the potential for encouraging students to work with mathematics in a motivating and exploratory manner. The change of students' argumentation speech in mathematics indicate a positive influence on their ability to articulate their mathematical ideas.

The project though, has to be meticulously scheduled and prepared since it's important for the students at this age to understand what is expected of them. Furthermore the project requires the cooperation of teachers of different specialities, which perquisites a good coordination and a common pace.

Teacher's beliefs and different teaching styles have not taken under consideration in the present study, although they are consist an influential factor in the way that mathematics knowledge is constructed. It would be interesting also to study the effects on the argumentation of students in a more longitudal research where the changes along the timeline would be explored.

\section{Acknowledgements}

The author would like to thank R. Georgantaki, A. Bakamitsou, P. Malliara and A. Vlachos for their help in the realization of the project. 


\section{References}

Anghileri, J. (2008). Developing Number Sense, London: Continuum.

Bikner-Ahsbahs, A. (2005). Mathematikinteresse zwischen Subjekt und Situation [Interest in mathematics between subject and situation]. Hildesheim, Berlin: Verlag Franzbecker.

Blumenfeld, P. C., Soloway, E., Marx, R. W., Krajcik, J. S., Guzdial, M., \& Palincsar, A. (1991). Motivating project based learning: Substaining the doing, supporting the learning. Educational Psychologist, 26(3/4), http://dx.doi.org/10.1080/00461520.1991.9653139

Bungum, B., Manshadi, S., \& Atle Lysne, D. (2014). Mathematical speech and practical action: a case study of the challenges of including mathematics in a school technology project, International Journal of Mathematical Education in Science and Technology. http://dx.doi.org/10.1080/0020739X.2014.914253

Cramer, J. (2001). Everyday argumentation and knowledge construction in mathematical tasks. In M. Pytlak, T. Rowland, \& E. Swoboda (Eds.), Proceedings of the Seventh Congress of the European Society for Research in Mathematics Education (pp. 141-150). University of Rzeszñw, Poland.

Evens, H., \& Houssart, J. (2004). 'Categorizing pupils' written answers to a mathematics test question: 'I know but I can't explain”. Educational Research, 46, 269-282. http://dx.doi.org/10.1080/0013188042000277331

Godden, D., \& Walton, D. (2007).Advances in the theory of argumentation schemes and critical questions. Informal Logic, 27, 267-292.

Krummheuer, G. (1995). The ethnography of argumentation. In P. Coblb \& H. Bauersfeld (Eds.), The emergence of mathematical meaning: Interaction in classroom cultures. Hillsdale, NJ: Lawrence Erlbaum.

Krummheuer, G., \& Brandt, B. (2001). Paraphrase und Traduktion. Partizipationstheoretische Elemente einer Interaktionstheorie des Mathematiklernens in der Grundschule [Paraphrase and tradition. Participation theoretical elements of an interaction theory of learning mathematics in elementary school]. Weinheim: Beltz.

Metaxas, N., Potari, D., \& Zachariades, (2009). T. Studing teachers' pedagogical argumentation. In Tzekaki, M., Kaldrimidou, M. \& Sakonidis, H. (Eds), Proceedings of the 33rd Conference of the International Group for the Psychology of Mathematics Education,Vol. 4, (pp. 121-128). Thessaloniki, Greece.

Nohda, N. (2000). Teaching by Open-Approach Method in Japanese Mathematics Classroom. In Proceedings of the PME-24 Conference (eds. T. Nakahara \& M. Koyama), Vol. 1, 39-53. Hiroshima University (Japan).

Pedemonte, B. (2007). How can the relationship between argumentation and proof be analysed?' Educational Studies in Mathematics, 66, 23-41. 
http://dx.doi.org/10.1007/s10649-006-9057-x

Pedemonte, B. (2008). Argumentation and algebraic proof. ZDM, 40(3), 385-400. http://dx.doi.org/10.1007/s11858-008-0085-0

Pehkonen, E. (1995). On pupils' reactions to the use of open-ended problems in mathematics. Nordic Studies in Mathematics Education, 3(4), 43-57.

Scardamalia, M., \& Bereiter, C. (1994).Computer supports for knowledge-building communities. The Journal of the Learning Sciences, 3, 265-283. http://dx.doi.org/10.1207/s15327809jls0303_3

Schwarz, B., Neumann, Y., Gil, J., \& Ilya, M. (2003). Construction of collective and individual knowledge in argumentative activity. The Journal of the Learning Sciences, 12(2), 219-256. http://dx.doi.org/10.1207/S15327809JLS1202_3

Stacey, K. (1995).The Challenges of Keeping Open Problem-Solving Open in School Mathematics. International Reviews on Mathematical Education, 27(2), 62-67.

Toulmin, S. (1996). The Uses of Argument. Cambridge University Press, Cambridge; 1958Means, M. L., \& Voss, J. F. Who reasons well? Two studies of informal reasoning among children of different grade, ability, and knowledge levels. Cognition and Instruction, 14, 139-179. http://dx.doi.org/10.1207/s1532690xci1402_1

Walton, D. (2006). Fundamentals of critical argumentation. New York: Cambridge University Press.

Walton, D., Reed, C., \& Macagno, F. (2008). Argumentation schemes. Cambridge: Cambridge University Press. http://dx.doi.org/10.1017/CBO9780511802034

Yackel, E. (2001). Explanation, justification and argumentation in mathematics classrooms. In: M. van den Heuvel-Panhuizen (ed.): Proceedings of the 25th International Conference on the Psychology of Mathematics Education, Vol. 1, pp. 9-23. Utrecht, Holland: IGPME.

Strunk, W., Jr., \& White, E. B. (1979). The elements of style (3rd ed.). New York: Macmillan, (Chapter 4).

Van der Geer, J., Hanraads, J. A. J., \& Lupton R. A. (2000). The art of writing a scientific article. Journal of Scientific Communications, 163, 51-59

\section{Copyright Disclaimer}

Copyright reserved by the authors.

This article is an open-access article distributed under the terms and conditions of the Creative Commons Attribution license (http://creativecommons.org/licenses/by/3.0/). 